\title{
DYNAMIKA PROCESU PAROWANIA POJEDYNCZEJ KROPLI WODY PRZY MAŁYCH LICZBACH WEBERA
}

\begin{abstract}
Jedną z metod chłodzenia powierzchni o dużej gęstości strumienia ciepła jest wykorzystanie rozpylaczy cieczowych. Proces odbioru ciepła rozpylonej cieczy zachodzi przez przemianę fazową płynu, którego tempo jest uzależnione od warunków początkowych, takich jak prędkość i średnica początkowa kropel cieczy. $\mathrm{W}$ artykule podjęto próbę obliczenia dynamiki procesu parowania pojedynczej kropli wody rozpylanej na płaskiej powierzchni ciała stałego, przy różnych liczbach Webera. Zaprezentowano model numeryczny odparowania wody oparty na metodzie lokalizacji powierzchni swobodnej Volume of Fluid (VoF). Symulację wykonano dla prędkości 1, 2, 3 i $4 \mathrm{~m} / \mathrm{s}$ oraz początkowych średnic kropel równych odpowiednio 100, 150 i $200 \mu \mathrm{m}$. Liczby We osiągnęły wartości od 1,35 do 32,35.
\end{abstract}

Słowa kluczowe: obliczenia numeryczne, rozpylacze cieczowe, dynamika parowania kropli

\section{Wstęp}

Zarówno układy elektroniczne, jak i aplikacje przemysłowe dużej mocy osiągają obecnie znaczne wartości przekazywanej energii cieplnej na jednostkę powierzchni. Do takich struktur można zaliczyć pręty paliwowe w reaktorach jądrowych, powierzchnie ogrzewalne w kotłach na parametry nadkrytyczne czy delikatne układy elektroniczne [4]. W przypadku tych ostatnich lokalne strumienie ciepła generowane przez mikroprocesory mogą osiągnąc w najbliższej przyszłości wartość $300 \mathrm{~W} / \mathrm{cm}^{2}$, przy wymaganej temperaturze pracy poniżej $85^{\circ} \mathrm{C}$ [1]. Do odbioru ciepła o dużej gęstości można wykorzystać różne techniki chłodzenia powierzchni, m.in. rozpylacze cieczowe. Stosowanie takich technologii odbioru strumieni cieplnych jest skutkiem ograniczeń wynikających z charakteru przejmowania ciepła przez konwekcję wymuszoną (dla gazów), a także limitu odbioru ciepła podczas wrzenia powierzchniowego, uzależnionego od charakte-

\footnotetext{
${ }^{1}$ Autor do korespondencji/corresponding author: Przemysław Smakulski, Politechnika Wrocławska, ul. Wybrzeże Wyspiańskiego 27, 50-370 Wrocław, tel.: (71) 3203091, e-mail: przemyslaw. smakulski@pwr.edu.pl.

2 Sławomir Pietrowicz, Politechnika Wrocławska, e-mail: slawomir.pietrowicz@pwr.edu.pl.
} 
rystyki wrzenia cieczy [10]. Biorąc pod uwagę pracę układów elektronicznych, trzeba zauważyć, że istotny z perspektywy efektywnej pracy procesorów jest czas chłodzenia. Wartości temperatury narastają (w zależności od mocy cieplnej przypadającej na jednostkę powierzchni) w czasie krótszym niż $0,1 \mathrm{~s}$ do temperatur granicznych dla pracy procesora [6]. Dlatego też jednym z istotnych elementów jest poznanie dynamiki parowania pojedynczej kropli, która ma wpływ na efektywność procesu, a co za tym idzie - na nakłady energetyczne przyszłej instalacji chłodniczej.

Celem artykułu jest analiza czynników mających wpływ na proces parowania pojedynczej kropli fazy ciekłej i odbiór ciepła od powierzchni chłodzonej przy różnych liczbach Webera.

\section{Proces parowania kropli wody przy zderzeniu z ciałem stałym}

Opierając się na badaniach Chandry i in. [3], można dostrzec wpływ kąta styku powierzchniowego na prędkość parowania kropli. Podczas uderzenia, w zależności od średnicy początkowej kropli oraz jej prędkości, wartość kąta zwilżenia ścianki jest zmienna $\mathrm{w}$ czasie formowania się powierzchni styku ciecz-ciało stałe. Dodatkowo, przy uderzeniu może dojść do odbicia, rozpłaszczenia lub rozpadu kropli cieczy [8] i tym samym do zmiany powierzchni kontaktu. Zależności te najlepiej wyrazić liczbą Webera, która wiąże w sobie jednocześnie prędkość kropli, jak i jej średnicę początkową [7].

$$
\mathrm{We}=\frac{\rho_{L} D v^{2}}{\sigma}
$$

gdzie: $\rho_{L}$ - gęstość cieczy, $D$ - średnica początkowa kropli, $v$ - prędkość, $\sigma$-napięcie powierzchniowe cieczy.

Bezwymiarowa liczba kryterialna - liczba Webera (We) - jest określana jako stosunek sił bezwładności do sił napięcia powierzchniowego dla cieczy. Jest wykorzystywana głównie do określenia energii uderzenia cieczy o powierzchnię. Na tej podstawie można przewidzieć zachowanie się cieczy tuż po uderzeniu o warstwę powierzchni. Krytyczna wartość liczby Webera określa ilość energii potrzebnej do rozerwania kropli na mniejsze frakcje. Niestety, nie ma jednoznacznej wartości liczby We, przy której istnieje pewność, że rozpad kropli nastąpi. W przypadku wody szacuje się, że krytyczna wartość liczby Webera oscyluje w okolicach 90 dla powierzchni pokrytej parafiną [9].

\section{Model parowania kropli wody}

W celu zamodelowania procesu parowania kropli wody posłużono się numeryczną metodą lokalizacji powierzchni swobodnej Volume of Fluid (VoF), która w bardzo dokładny sposób przybliża zachowanie się przepływu dwufazo- 
wego złożonego z frakcji ciekłej i gazowej [5]. Metoda ta polega na identyfikacji wewnątrz struktury siatki numerycznej, objętości zajmowanej przez fazę ciekłą. Przypisuje ona każdej komórce siatki wartości od 0 do 1, które reprezentują stosunek udziału objętościowego cieczy do objętości całej komórki $\left(\alpha_{1}\right)$. Traktując mieszaninę gazów jako płyny nieściśliwe, można opisać rozkład pola temperatur równaniem energii:

$$
\frac{\partial}{\partial t} T+\nabla \bullet(U T)=D T \nabla^{2} T+\frac{S_{h}}{\rho c_{p}}
$$

gdzie: $T$ - temperatura w K, $U$ - wektor prędkości, $S_{h}$ - człon źródłowy zależny od procesu parowania, $\rho$-gęstość mieszaniny, $c_{p}$ - ciepło właściwe mieszaniny.

Strumień energii cieplnej związany z przejściem fazowym opisano za pomocą iloczynu ubytku strumienia masy $m_{l v}$ (w przypadku parowania) i utajonego ciepła parowania dla cieczy $L$ [12]. Iloczyn ten w zależności od przypadku (kondensacja/parowanie) stanowi dodatkowy człon źródłowy wchodzący w skład głównego równania energii (2):

$$
S_{h}= \begin{cases}-\dot{m}_{l v} L & \text { parowanie } \\ \dot{m}_{l v} L & \text { kondensacja }\end{cases}
$$

gdzie: $L$ - ciepło utajone parowania dla cieczy, $m_{l v}$ - strumień masy cieczy związany z przejściem fazowym.

Rozpatrując zagadnienie wnikania ciepła, ubytek masy frakcji ciekłej podczas parowania można określić za pomocą stosunku ciepła dostarczonego poprzez konwekcję oraz dyfuzję do ciepła utajonego przejścia fazowego. Jako temperaturę odniesienia przyjęto stałą temperaturę nasycenia wody:

$$
-\dot{m}_{l v}=\frac{\dot{Q}_{c o n v}}{L}=\frac{h_{c o n v} A_{\text {inter }}\left(T-T_{\text {sat }}\right)}{L}
$$

gdzie: $h_{\text {conv }}$ - konwekcyjny współczynnik wnikania ciepła, $A_{\text {inter }}$ - powierzchnia wymiany ciepła/powierzchnia kropli cieczy, $T_{\text {sat }}$ - temperatura nasycenia dla wody.

Konwekcyjny współczynnik $h_{\text {conv }}$ parowania powierzchniowego kuli zaproponowany przez Bejana [2] zastosowano do obliczeń i przedstawiono we wzorze:

$$
h_{\text {conv }}=\frac{\lambda_{2}}{D} 0,67\left[\frac{D^{3} L g\left(\rho_{1}-\rho_{2}\right)}{\lambda_{2} v_{2}\left(T-T_{\text {sat }}\right)}\right]^{1 / 4}
$$


gdzie: $\lambda_{2}$ - współczynnik przewodzenia ciepła dla cieczy, $D$ - średnica kropli, $\rho_{1}, \rho_{2}-$ gęstość odpowiednio wody i powietrza, $g$ - przyspieszenie ziemskie, $v_{2}$ - lepkość kinematyczna dla powietrza.

\section{Warunki symulacji}

Obliczenia numeryczne wykonano, korzystając z oprogramowania OpenFOAM 2.3.0 i wykorzystując do obliczeń model identyfikacji powierzchni swobodnej Volume of Fluid (VoF). Kropla wody uderza w płaską powierzchnię (rys. 1.) z prędkością początkową odpowiednio 1, 2, 3 i $4 \mathrm{~m} / \mathrm{s}$. Powierzchnia ciała stałego, o które uderza kropla, wytwarza strumień ciepła o wartości równej $100 \mathrm{~W} / \mathrm{cm}^{2}$, co odpowiada średniej wartości pracy procesorów komputerowych przy niskim obciążeniu mocy. Ciśnienie oraz parametry strumienia cieplnego pozostają stałe przez cały czas trwania obliczeń.

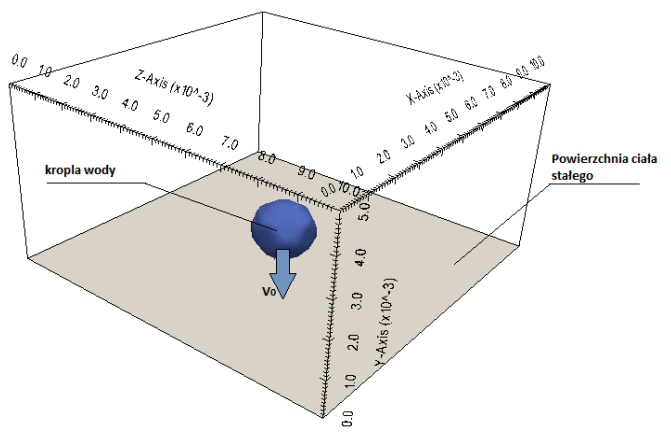

Rys. 1. Domena $\mathrm{z}$ zaznaczoną powierzchnią ciała stałego

Fig. 1. The domain with marked surface of solid body

Krople wody o początkowej temperaturze $10^{\circ} \mathrm{C}$ i średnicach odpowiednio 100,150 i $200 \mu \mathrm{m}$ zostały uniesione nad powierzchnię o zadanym strumieniu ciepła. Nadano im początkową wartość prędkości, zmieniając tym samym liczbę Webera przed uderzeniem. Kropla spadała pod kątem $90^{\circ}$ do powierzchni ciała stałego. Liczba We została tak dobrana, aby zapobiec wtórnemu rozpadowi kropli (wartość We poniżej 90). Domena siatki numerycznej została wykonana jako prostopadłościan o bokach 1 x 1 x 0,5 mm. Do obliczeń zastosowano siatkę heksagonalną o 100 tys. elementów obliczeniowych.

\section{Wyniki symulacji}

Symulację przeprowadzono dla średniego czasu formowania się kształtu kropli wody na powierzchni ciała stałego, dochodzącego do $25 \mathrm{~ms}$ [11]. Po tym czasie w większości przypadków tempo parowania kropli jest stałe. Dynamikę parowania kropli wody określono za pomocą udziału objętościowego wody wewnątrz siatki numerycznej, który malał wraz z ubytkiem masy kropli wody w czasie (rys. 2.). Stosunek ubytku udziału objętościowego określono względem 
początkowego udziału objętościowego wody (stosunek $\alpha / \alpha_{0}$ na wykresach). $\mathrm{Na}$ podstawie wygenerowanych wyników zauważono, że w czasie poniżej $10 \mathrm{~ms}$ dynamika procesu parowania ma charakter nieustalony i jest uzależniona od kształtu uformowanego krążka cieczowego. Po czasie formowania się kropli (rys. 3b) następuje etap ustalonego charakteru parowania. Ubytek masy cieczy jest wprost proporcjonalny do redukcji średnicy kropli - zgodnie z prawem $D^{2}$ [7]. Początkowa średnica kropli wpływa na proces parowania (rys. 2.). Zasadniczo, im mniejsza kropla cieczy, tym proces parowania jest krótszy. Na rysunkach 3. i 4., jak i w pozostałych przypadkach, kropla wody ulega deformacji w memencie styku z ciałem stałym. Przy różnych liczbach We dochodzi do różnego rodzaju deformacji. Przy liczbach We ok. 24-32 (rys. 4a) średnica kropli osiąga swoje maksimum po czasie równym $1 \mathrm{~ms}$. Jak można zauważyć na rys. 5-7, tempo parowania, w zakresie nieustalonym (do $25 \mathrm{~ms}$ ), jest znacząco

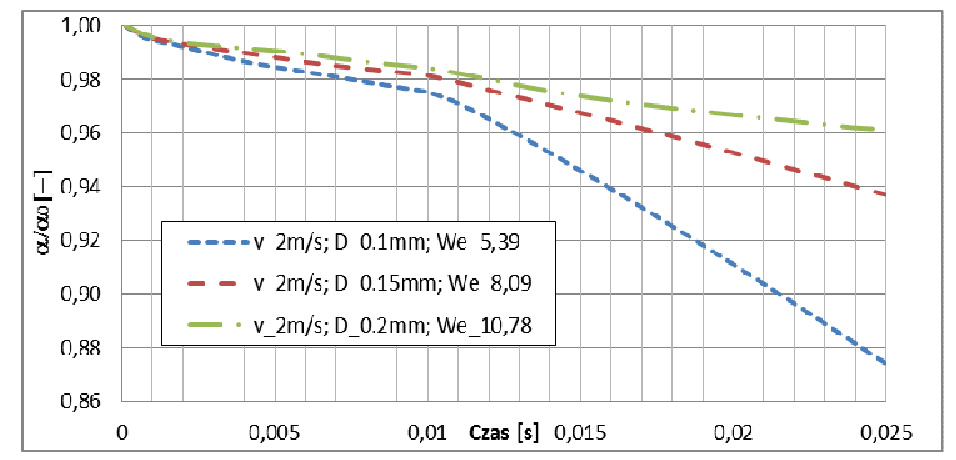

Rys. 2. Porównanie tempa parowania kropli wody przy różnych średnicach i tej samej prędkości początkowej

Fig. 2. Comparison of the droplet evaporation rate for different droplet diameters, with the same initial velocity

a)

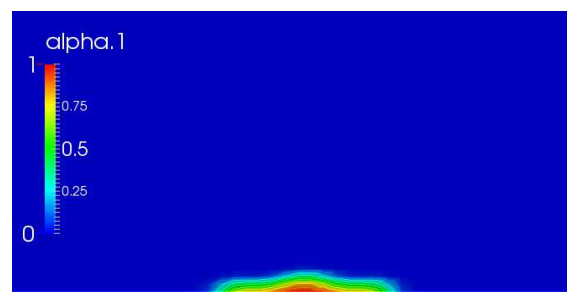

b)

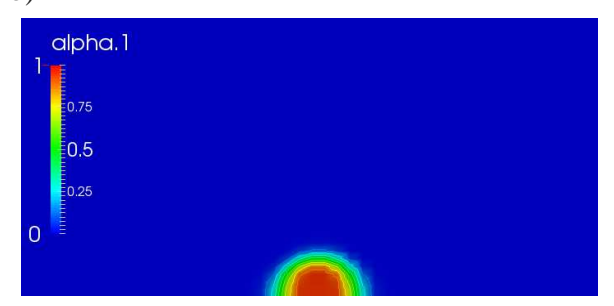

Rys. 3. Profil udziału objętościowego wody w czasie: a) $1 \mathrm{~ms}$, b) $10 \mathrm{~ms}$; średnica początkowa $100 \mu \mathrm{m}$, prędkość początkowa $2 \mathrm{~m} / \mathrm{s}, \mathrm{We}=5,39$

Fig. 3. The water volume fraction profile at time of a) $1 \mathrm{~ms}$, b) $10 \mathrm{~ms}$; initial droplet diameter is $100 \mu \mathrm{m}$, initial velocity is $2 \mathrm{~m} / \mathrm{s}, \mathrm{We}=5.39$ 
a)

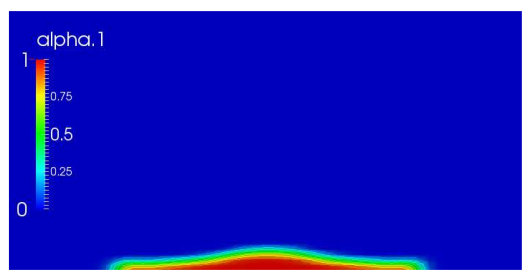

b)

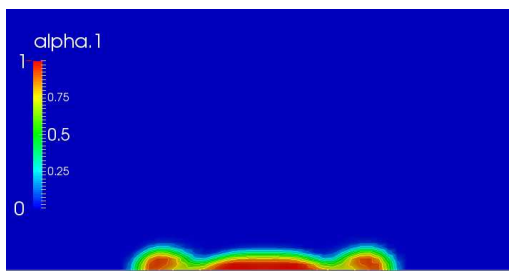

Rys. 4. Profil udziału objętościowego wody w czasie: a) $1 \mathrm{~ms}$, b) $5 \mathrm{~ms}$; średnica początkowa $200 \mu \mathrm{m}$, prędkość początkowa $3 \mathrm{~m} / \mathrm{s}$, We = 24,26

Fig. 4. The water volume fraction profile at time of a) $1 \mathrm{~ms}$, b) $5 \mathrm{~ms}$; initial droplet diameter is $200 \mu \mathrm{m}$, initial velocity is $3 \mathrm{~m} / \mathrm{s}, \mathrm{We}=24.26$

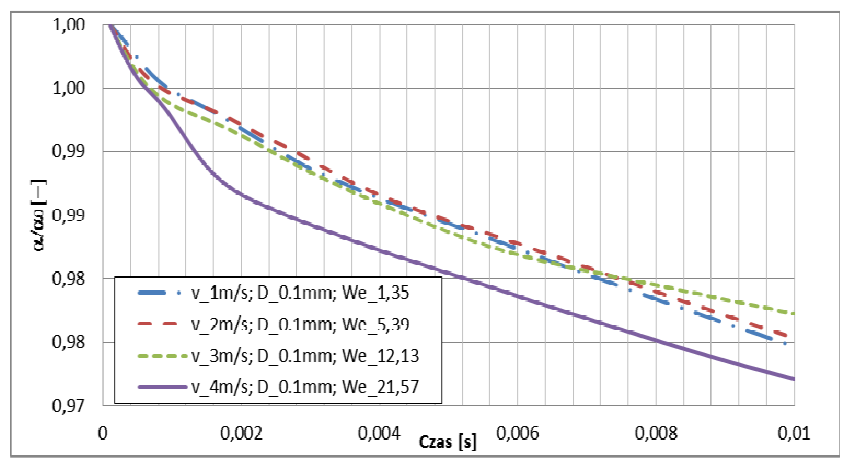

Rys. 5. Dynamika parowania kropli wody przy średnicy początkowej kropli $100 \mu \mathrm{m}$

Fig. 5. Droplet evaporation dynamics for the initial droplet diameter $100 \mu \mathrm{m}$

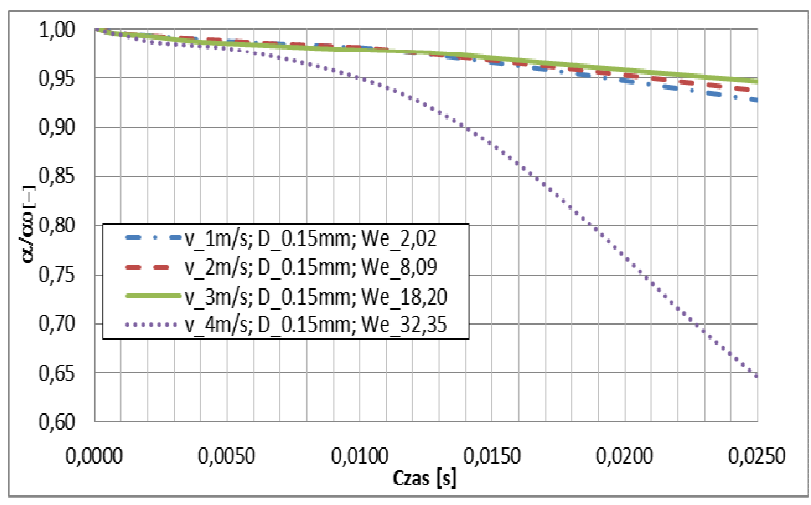

Rys. 6. Dynamika parowania kropli wody przy średnicy początkowej kropli $150 \mu \mathrm{m}$

Fig. 6. Droplet evaporation dynamics for the initial droplet diameter $150 \mu \mathrm{m}$ 


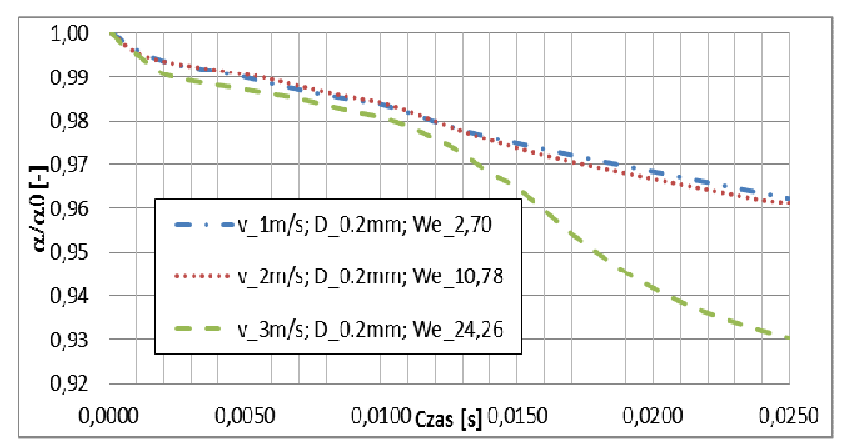

Rys. 7. Dynamika parowania kropli wody przy średnicy początkowej kropli $200 \mu \mathrm{m}$

Fig. 7. Droplet evaporation dynamics for the initial droplet diameter $200 \mu \mathrm{m}$

szybsze przy wartościach liczby We powyżej 20. Jest to spowodowane uformowanym kształtem powierzchni styku pomiędzy kroplą a ciałem stałym. Ponadto, wcześniejsze formowanie się krążka cieczowego o stosunkowo dużej powierzchni i najniższej możliwej wysokości ułatwia proces podgrzewania do temperatury nasycenia dla cieczy.

\section{Podsumowanie}

Zaprezentowane wyniki ukazują dynamikę procesu parowania pojedynczej kropli wody przy różnych wartościach liczby Webera. Przedstawiona analiza prezentuje charakter parowania kropli cieczy zarówno podczas ustalonego, jak i nieustalonego parowania kropli (tuż po uderzeniu i formowaniu się krążka cieczy). Zauważono, że przy zaproponowanych średnicach początkowych kropli charakterystyka parowania cieczy zależy od kształtu powierzchni styku pomiędzy wodą a ciałem stałym. Przy wartościach liczby We powyżej 20 charakterystyka parowania jest bardziej dynamiczna od pozostałych. Tempo parowania podczas odbioru ciepła ma zasadniczy wpływ na bezwładność układu chłodzenia. Dlatego też niezbędne jest dokładne zrozumienie procesu parowania rozpylonej cieczy w celu usprawnienia odbioru ciepła od powierzchni chłodzonej.

\section{Literatura}

[1] Agostini B., Fabbri M., Park J.E., Wojtan L., Thome J.R., Michel B.: State of the art of high heat flux cooling technologies, Heat Transf. Eng., 28 (2007), 258-281.

[2] Bejan A.: Convective heat transfer, Wiley, New York 2004.

[3] Chandra S., Di Marzo M., Qiao Y., Tartarini P.: Effect of liquid-solid contact angle on droplet evaporation, Fire Saf. J., 27 (1996), 141-158. 
[4] Chunqiang S., Shuangquan S., Changqing T., Hongbo X.: Development and experimental investigation of a novel spray cooling system integrated in refrigeration circuit, Appl. Therm. Eng., 33-34 (2012), 246-252.

[5] Hirt C., Nichols B.: Volume of fluid (VOF) method for the dynamics of free boundaries, J. Comput. Phys., 39 (1981), 201-225.

[6] Huang W.: An improved block-based thermal model in hotspot 4.0 with granularity considerations, Proc. Int. Cond. WDDD’07, San Diego 2007.

[7] Orzechowski Z., Prywer J.: Wytwarzanie i zastosowanie rozpylonej cieczy, WNT, Warszawa 2008.

[8] Rein M.: Phenomena of liquid drop impact on solid and liquid surfaces, Fluid Dyn. Res., 12 (1993), 61-93.

[9] Šikalo Š., Marengo M., Tropea C., Ganić E.: Analysis of impact of droplets on horizontal surfaces, Exp. Therm. Fluid Sci., 25 (2002), 503-510.

[10] Smakulski P.: Method of high heat flux removal by usage of liquid spray cooling, Arch. Thermodyn., 34 (2013), 173-184.

[11] Strotos G., Gavaises M.: Numerical investigation on the evaporation of droplets depositing on heated surfaces at low Weber numbers, Heat Mass Transf., 51 (2008), 1516-1529.

[12] Sun D.L., Xu J.L., Wang L.: Development of a vapor-liquid phase change model for volume-of-fluid method in FLUENT, Int. Commun. Heat Mass Transf., 39 (2012), 1101-1106.

\title{
EVAPORATION PROCESS DYNAMICS OF SINGLE WATER DROPLET AT LOW WEBER NUMBERS
}

\begin{abstract}
S u m m a r y
One of the cooling methods for high heat flux surfaces is the spray cooling method. The heat removal process of sprayed liquid occurs by the phase transformation of liquid, whose rate depends on the initial conditions such as velocity and initial diameter of the liquid droplets. The article shows the attempt to calculate the evaporation process dynamics of single water droplet spraying on flat surface of solid body at different Weber numbers. The numerical model of water evaporation based on the location of the free surface method - Volume of Fluid (VoF), was presented in this paper. Calculations were performed for the velocities of $1,2,3$, and $4 \mathrm{~m} / \mathrm{s}$, and initial droplets diameter of 100, 150 and $200 \mu \mathrm{m}$. The value of the Weber number were from 1.35 to 32.35 .
\end{abstract}

Keywords: numerical calculations, liquid sprayer, drop evaporation dynamics

DOI: $10.7862 / \mathrm{rm} .2015 .16$

Otrzymano/received: 14.09.2014 r.

Zaakceptowano/accepted: 20.02.2015 r. 